\title{
ANALYSIS OF PLANE WAVE COUPLING TO MULTI-CONDUCTOR LINE ABOVE LOSSY SOIL
}

\author{
Vesna Arnautovski-Toševa ${ }^{1}$, Leonid Grčev ${ }^{1}$, Khalil El Khamlichi Drissi ${ }^{2}$ \\ ${ }^{1}$ Faculty of Electrical Engineering and Information Technologies, \\ "Ss. Cyril and Methodius" University in Skopje, \\ Rugjer Bošković bb, P.O. box 574, 1001 Skopje, Republic of Macedonia \\ ${ }^{2}$ Institute Pascal, Blaise Pascal University, Clermont-Ferrand, France \\ atvesna@feit.ukim.edu.mk
}

\begin{abstract}
A b s t r a c t: The paper presents comparison between rigorous electromagnetic model and two approximate approaches of modeling plane wave coupling to multi-conductor horizontal line above a homogeneous lossy soil. The first approximate approach is based on quasi-static complex image theory $(\mathrm{CI})$ and the second approximate approach uses transmission line theory (TL). Our objective is to analyze the numerical error when calculating the current distribution by when using the proposed approximate models. Here, the reference results are obtained by using the electromagnetic model (EM) that is based on the full-wave theory and thus developed on least theoretical neglects. The numerical results of detailed parametric analysis indicate the frequency range of applicability of the proposed approximate models with rms error of the current distribution less than $10 \%$.
\end{abstract}

Key words: electromagnetic theory; complex image theory; transmission line theory

\section{АНАЛИЗА НА ПОВЕКЕСПРОВОДНИЧКИ ВОД НАД ХОМОГЕНА ЗЕМЈА ПРИ ПОБУДА ОД РАМНИНСКИ БРАН}

А п с т р а к т: Во трудот е претставена споредба помеѓу електромагнетниот модел и два приближни модели за анализа на повеќеспроводнички надземен вод при побуда од рамнински бран. Првиот апроксимативен модел се базра врз квази-статичката теорија на комплексни ликови, додека другиот апроксимативен модел се базира врз теоријата на водови. Целта е да се анализира нумеричката грешка при пресметка на распределбата на електричната струја надолж спроводниците со примена на приближните постапки на моделирање. Референтните резултати се добиени со примена на електромагнетниот модел кој е базиран врз електромагнетната теорија, а со тоа базиран врз најмалку теориски занемарувања. Нумеричките резултати добиени врз основа на детална параметриска анализа покажуваат во кој фреквенциски опсег пресметката на распределбата на електричната струја со примена на предложените приближни модели е со грешка помала од $10 \%$.

Клучни зборови: електромагнетна теорија, теорија на комплексни ликови, теорија на водови

\section{INTRODUCTION}

PLANE wave coupling to overhead multiconductor line is often part of EMC studies [1-5]. The work is mainly based on transmission line theory (TL) whose main advantages are simplicity, efficiency and low computational cost. However, the most accurate solution of above problem is based on electromagnetic theory [6-7]. This, so called exact approach, is based on rigorous formulation for the electric field of a Hertz dipole, which involves Green's functions that take into account the influence of the soil-air interface in exact Sommerfeld formulation. However, because of time consuming and inefficient direct numerical integration, various approximate approaches have been proposed in order to achieve fast and efficient closed-form expressions [8-12]. 
The paper represents continuation of author's research in approximate modeling of thin-wire conductors in presence of lossy soil at high frequencies [13-15]. The main objective of this work is to validate the proposed complex image and transmission line models for a given problem with respect to frequency, geometry and soil parameters.

\section{MATHEMATICAL MODEL}

Consider $x$-directed horizontal line consisted of $i=1,2,3$ parallel thin-wire conductors of radius $a$ and length $L$ located at mutual distance $d_{y}$ and height $h_{i}$ above homogeneous lossy soil. Figure 1 represents a case of a two-conductor line $(k=2)$ in $x-z$ plane and $x-y$ plane respectively. The air (medium " 0 ") occupies the upper half-space $(z>0)$, and homogeneous lossy soil occupies the lower half-space $(z<0)$. The lossy soil is characterized by permittivity $\varepsilon=\varepsilon_{0} \varepsilon_{r}$, permeability $\mu_{0}$ and conductivity $\sigma$. The excitation is assumed by $x$-directed electric field $E^{i}$ of normal incidence in frequency range from $0.1 \mathrm{MHz}$ to $10 \mathrm{MHz}$.

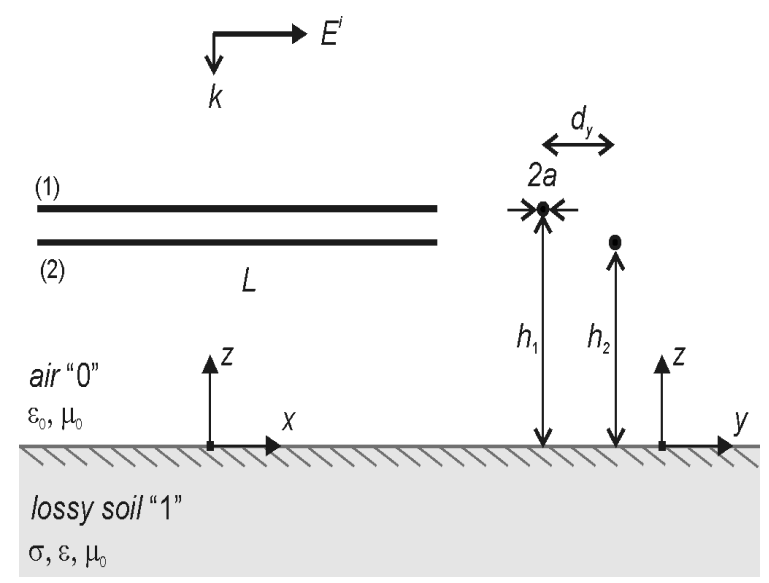

Fig. 1. Two-conductor line above homogeneous lossy soil excited by plane wave electric field of normal incidence.

\section{ELECTROMAGNETIC MODEL}

To solve induced currents for a given problem we develop a Moment Method based electromagnetic (EM) model. The wire conductors are segmented in fictitious segments and the current distribution is approximated by overlapped triangular expansion functions [16]. Solving the matrix equation $[Z] \cdot[I]=[U]$ yields the current distribution [17]. Here, the column matrix $[I]$ represents the unknown current samples, $[Z]$ is generalized impedance matrix of mutual impedances between triangular dipoles, and $[U]$ is the excitation column matrix.

The excitation is assumed by a plane wave of normal incidence with $x$-directed electric field vector of intensity (time variation is assumed and suppressed). The elements of matrix $[U]$ are determined by $U_{n}=\int_{l_{n}} E d l_{n}$, where $E$ is an $x$-directed electric field (incident and reflected) tangential to the wire segment $l_{n}$ given by

$$
\begin{aligned}
& E=E_{0}\left[1+R^{01} \exp \left(-j 2 k_{0} h_{k}\right)\right] \exp \left(j k_{0} h_{k}\right) \\
& R^{01}=\frac{1-\sqrt{\underline{\varepsilon}_{r}}}{1+\sqrt{\underline{\varepsilon}_{r}}} ; \quad \underline{\varepsilon}_{r}=\left(\varepsilon_{r}-j \sigma \omega^{-1}\right) \varepsilon_{0}^{-1} .
\end{aligned}
$$

The elements of the impedance matrix $z_{m n}$, represent mutual impedances between pairs of segments, observation $(m)$ and source $(n)$

$$
z_{m n}=\frac{V_{m n}}{I_{n}}=\frac{-1}{I_{n}} \int_{l_{m}} E_{n x} d l_{m x} .
$$

Here, $E_{n x}$ is $x$-directed component of the electric field vector tangential to the surface of the observation segment $m$ due to filaments of current $I_{n}$ and charge $q_{n}$ along the axis of the source segment $n$ that is formulated by Mixed Potential Integral Equation (MPIE) [19]

$$
\begin{gathered}
E_{n x}=-j \omega A_{n x}-\nabla V_{n}, \\
A_{m x}=\int_{l_{m}} G_{A}^{x x} I_{m} d l_{m x} \text { and } V_{m}=\int_{l_{m}} G_{V} q_{m} d l_{m x} .
\end{gathered}
$$

Here, $G_{A}^{x x}$ stands for the $x$-component of the magnetic vector potential dyadic Green's function due to a $x$-directed horizontal electric dipole HED above lossy soil. Respectively, $G_{V}$ is the scalar potential Green's function due to one charge associated to the HED.

The full-wave model involves exact Sommerfeld formulations of the corresponding Green's functions. They are obtained firstly in the transformed Fourier domain by solving the corresponding wave equations with respect to the boundary conditions at the air-soil interface [19]. The spatial domain Green's functions are later obtained by the following Sommerfeld-type integral 


$$
G_{A, V}=S_{0}\left\{\tilde{G}_{A, V}\right\}=\frac{1}{2 \pi} \int_{0}^{\infty} \tilde{G}_{A, V}(\lambda) J_{0}(\lambda \rho) \lambda d \lambda
$$

where $\tilde{G}_{A, V}$ is spectral domain Green's function, $J_{0}(\lambda \rho)$ is zero-order Bessel function of the first kind, and $\rho$ is radial distance between HED and observation point.

The exact formulations of the Green's functions related to this problem are

$$
\begin{aligned}
G_{A}^{x x} & =\frac{\mu_{0}}{2}\left[G_{d}+S_{0}\left\{R_{T E} \frac{\exp \left[-u_{0}\left(z+h_{k}\right)\right]}{u_{0}}\right\}\right], \\
G_{V} & =\frac{1}{2 \varepsilon_{0}}\left[G_{d}+\right. \\
& +S_{0}\left\{\frac{k_{0}^{2} R_{T E}-u_{0}^{2} R_{T M}}{\lambda^{2}} \frac{\exp \left[-u_{0}\left(z+h_{k}\right)\right]}{u_{0}}\right\} .
\end{aligned}
$$

The first term in (6) and (7) is so called direct term that represents a spherical wave radiated by a Hertz dipole in unbounded free-space

$$
G_{d}=S_{0}\left\{\frac{\exp \left[-u_{0}\left(z-h_{k}\right)\right]}{u_{0}}\right\}=\frac{\exp \left(-j k_{0} R_{d}\right)}{2 \pi R_{d}} .
$$

Here $R_{d}=\sqrt{\rho^{2}+\left(z-h_{k}\right)^{2}}$ is distance between source HED at height $h_{k}$ and observation point at height $z$ above soil. The second term $S_{0}\{\cdot\}$ in (6) and (7) represents the wave reflected form finitely conductive homogeneous soil. The terms $R_{T E}$ and $R_{T M}$ stand for the Fresnel reflection coefficients with TM and TE wave polarization [20], where $k_{0}$ and $k_{1}$ are propagation constants of the air and the soil respectively,

$$
\begin{aligned}
& R_{T E}=\frac{u_{0}-u_{1}}{u_{0}+u_{1}} ; \quad R_{T M}=\frac{k_{1}^{2} u_{0}-k_{0}^{2} u_{1}}{k_{1}^{2} u_{0}+k_{0}^{2} u_{1}} ; \\
& u_{i}=\sqrt{\lambda^{2}-k_{i}^{2}} ; \quad i=0,1 ; \\
& k_{0}^{2}=\omega^{2} \mu_{0} \varepsilon_{0} ; \quad k_{1}^{2}=\underline{\varepsilon}_{r} k_{0}^{2} .
\end{aligned} .
$$

Computationally, the model is solved by using the method of moments and direct numerical integration of Sommerfeld integrals similarly to the approach in [7]. Thus, for a given excitation by plane wave of normal incidence we obtain the current distribution along the conductor.

\section{COMPLEX IMAGE MODEL}

In this section we give the mathematical expressions of the complex image model. This approach is based on exponential approximation of Sommerfeld integrals in (6) and (7) [8]. This leads to closed-form solution of the corresponding Green's functions $G_{A}^{x x}, G_{V}$ related to the fields radiated by the image and the complex image of the source HED [15]. When $\omega \rightarrow 0$ and $k_{0}^{2} \rightarrow 0$, we assume the following approximations [21, 22]:

$$
\begin{aligned}
& R_{T E} \rightarrow \frac{\lambda-u_{1}}{\lambda+u_{1}} \approx-\exp (-\lambda d) \approx-\exp \left(-u_{0} d\right), \\
& R_{T M} \rightarrow K=\frac{k_{1}^{2}-k_{0}^{2}}{k_{1}^{2}+k_{0}^{2}},
\end{aligned}
$$

where $d=2 / u_{1}=2 / \sqrt{j \omega \mu_{0}(\sigma+j \omega \varepsilon)}$ stands for the complex depth.

Now, it is possible to reduce (6) and (7) by using the following closed-form expressions

$$
\begin{aligned}
G_{A}^{x x} & =\frac{\mu_{0}}{2}\left[G_{d}-\right. \\
& \left.-\frac{1}{2 \pi} \int_{0}^{\infty} \frac{\exp \left\{-u_{0}\left[z+h_{k}+d\right]\right\}}{u_{0}} J_{0}(\lambda \rho) \lambda d \lambda\right] \\
& =\frac{\mu_{0}}{2}\left[\frac{\exp \left(-j k_{0} R_{d}\right)}{2 \pi R_{d}}-\frac{\exp \left(-j k_{0} R_{C i}\right)}{2 \pi R_{C i}}\right] \\
& =\frac{\mu_{0}}{2}\left[G_{d}-G_{C i}\right] . \\
G_{V} & =\frac{1}{2 \varepsilon_{0}}\left[G_{d}-\right. \\
& \left.-K \frac{1}{2 \pi} \int_{0}^{\infty} \frac{\exp \left[-u_{0}\left(z+h_{k}\right)\right]}{u_{0}} J_{0}(\lambda \rho) \lambda d \lambda\right] \\
& =\frac{1}{2 \varepsilon_{0}}\left[\frac{\exp \left(-j k_{0} R_{d}\right)}{2 \pi R_{d}}-K \frac{\exp \left(-j k_{0} R_{i}\right)}{2 \pi R_{i}}\right] \\
& =\frac{1}{2 \varepsilon_{0}}\left[G_{d}-K G_{i}\right] .
\end{aligned}
$$

where

$$
\begin{aligned}
& R_{i}=\sqrt{\rho^{2}+\left(z+h_{k}\right)^{2}} \\
& R_{C i}=\sqrt{\rho^{2}+\left(z+h_{k}+d\right)^{2}}
\end{aligned}
$$


stand respectively for the distance between the images of the source HED located at depth $-h_{k}$, and at complex depth $-\left(h_{k}+d\right)$.

\section{TRANSMISSION LINE MODEL}

The transmission line equations for a given problem can be derived from the Maxwell's equations and expressed in terms of voltage and current induced along the conductors [6].

$$
\begin{aligned}
& \frac{\partial \boldsymbol{V}(x)}{\partial x}+\boldsymbol{Z I}=\boldsymbol{E}(x, y, h), \\
& \frac{\partial \boldsymbol{I}(x)}{\partial x}+\boldsymbol{Y} \boldsymbol{V}(x)=0 .
\end{aligned}
$$

The mathematical details regarding the solution of the transmission line equations are based on chain matrices. Here $\boldsymbol{Z}$ and $\boldsymbol{Y}$ are $n \times n$ matrices and $\boldsymbol{I}, \boldsymbol{V}$ and $\boldsymbol{E}$ are $n$ dimensional vector columns.

The elements of the impedance matrix $\boldsymbol{Z}$ are per unit length self and mutual impedances $Z_{m m}$ and $Z_{m n}$ determined by [23]

$$
\begin{aligned}
Z_{m m} & =\frac{j \omega \mu_{0}}{2 \pi}\left[\ln \frac{2 h_{m}}{a}+\ln \frac{1+\gamma_{1} h_{m}}{\gamma_{1} h_{m}}\right], \\
Z_{m n} & =\frac{j \omega \mu_{0}}{2 \pi}\left[\ln \frac{\sqrt{\left(h_{m}+h_{n}\right)^{2}+d_{y}^{2}}}{\sqrt{\left(h_{m}-h_{n}\right)^{2}+d_{y}^{2}}}\right. \\
& \left.+\ln \frac{\sqrt{\left(h_{m}+h_{n}+d\right)^{2}+d_{y}^{2}}}{\sqrt{\left(h_{m}+h_{n}\right)^{2}+d_{y}^{2}}}\right] .
\end{aligned}
$$

The admittance matrix $\boldsymbol{Y}=j \omega \boldsymbol{C}=j \omega \operatorname{inv}(\boldsymbol{P})$ is determined by using the elements of matrix $\boldsymbol{P}$ :

$$
\begin{gathered}
P_{m m}=\frac{1}{2 \pi \varepsilon_{0}} \ln \frac{2 h_{m}}{a}, \\
P_{m n}=\frac{1}{2 \pi \varepsilon_{0}} \ln \frac{\sqrt{\left(h_{m}+h_{n}\right)^{2}+d_{y}^{2}}}{\sqrt{\left(h_{m}-h_{n}\right)^{2}+d_{y}^{2}}} .
\end{gathered}
$$

By combining with the boundary conditions $I(0)=I(L)=0$, the solution of (13) leads to the following matrix expression for the current distribution

$$
\boldsymbol{I}(x)=\boldsymbol{C}_{2} \exp (-\gamma x)+\boldsymbol{C}_{1} \exp (\gamma x)+\boldsymbol{C}_{3} \exp \left(u_{0} x\right),
$$

where $\exp (-\gamma x), \exp (\gamma x), \exp \left(u_{0} x\right)$ and $\sinh (\gamma L)$ are $n \times n$ diagonal matrices $\boldsymbol{P}$,

$$
\begin{aligned}
& \boldsymbol{A}=-\boldsymbol{Y} \frac{\operatorname{inv}\left(\gamma^{2}\right) \cdot \operatorname{inv}(\sinh (\gamma L))}{2} \boldsymbol{E}, \\
& \boldsymbol{C}_{1}=\boldsymbol{A}[1-\exp (-\gamma L)] \\
& \boldsymbol{C}_{2}=\boldsymbol{A}[\exp (-\gamma L)-1], \\
& \boldsymbol{C}_{3}=-\boldsymbol{A}
\end{aligned}
$$

where $\gamma^{2}=\operatorname{inv}(\boldsymbol{T}) \mathbf{Y Z T}$ is $n \times n$ diagonal matrix which contains the eigenvalues of $\boldsymbol{Y Z}$, and $\boldsymbol{T}$ is a matrix which contains the eigenvectors of $\boldsymbol{Y Z}$ [24].

\section{NUMERICAL RESULTS}

The applicability of the approximate CI and TL models is analyzed by comparing the induced currents along a multi-conductor horizontal line above homogeneous lossy soil excited by plane wave electric field of normal incidence.

The studied test-cases consider $k=1,2$ and 3 conductors of length $L=200 \mathrm{~m}$ and radius $a=0.007 \mathrm{~m}$. The geometry details of the test-cases are given in Figure 2. In our analysis we assume three values for the soil conductivity: $\sigma=0.001 \mathrm{~S} / \mathrm{m}$, $\sigma=0.01 \mathrm{~S} / \mathrm{m}$ and $\sigma=0.1 \mathrm{~S} / \mathrm{m}$. The relative permittivity of the soil is fixed at $\varepsilon_{r}=10$. The electric field intensity is $E_{0}=1 \mathrm{~V} / \mathrm{m}$ in frequency range from $0.1 \mathrm{MHz}$ to $10 \mathrm{MHz}$.

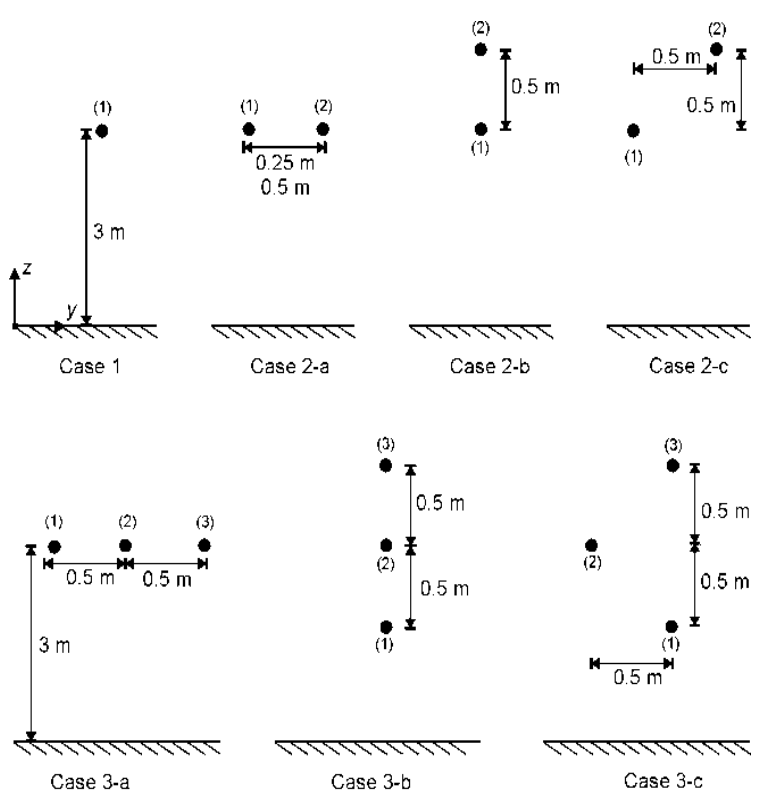

Fig. 2. Geometry of the studied test-cases of 1,2 or 3 conductors 
The accuracy of CI and TL models is analyzed in frequency domain by comparing the currents along the conductors using the following normalized rms error [25] where $\underline{I}_{E M i}$ and $\underline{I}_{a p p r o x i}$ are, respectively, phasors of $N$ current samples along the conductors computed by using rigorous EM model, and CI and TL models respectively. Here also we compare the currents calculated by using Numerical Electromagnetics Code (NEC) reflection coefficient solution [27]

$$
\varepsilon_{r m s}=\left[\frac{\sum_{i=1}^{N}\left|\underline{I}_{E M i}-\underline{I}_{a p p r o x i}\right|^{2}}{\sum_{i=1}^{N}\left|\underline{I}_{E M i}\right|^{2}}\right]^{1 / 2} .
$$

\section{Single-conductor line}

Firstly we analyze the case of a single conductor $k=1$ (Case 1). The soil conductivity is assumed $0.01 \mathrm{~S} / \mathrm{m}$.

Figure 3 shows the induced current (magnitude and phase) along the studied single conductor at $1 \mathrm{MHz}$ and $10 \mathrm{MHz}$. As may be observed, the results obtained by CI and TL models are in very good accordance with EM model. However, more significant difference is obtained by NEC reflection coefficient method.

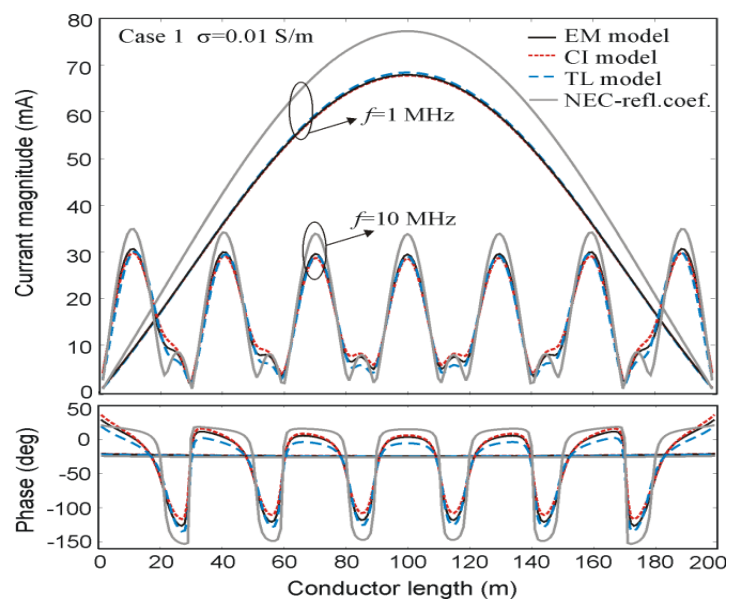

Fig. 3. Current distribution at $1 \mathrm{MHz}$ and $10 \mathrm{MHz}$ for Case 1 $(\sigma=0.01 \mathrm{~S} / \mathrm{m})$

Figure 4 shows the variation of the current magnitude at the center of the conductor $(x=L / 2=$ $100 \mathrm{~m}$ ) with respect to frequency. The maximal values of the current correspond to resonant frequencies roughly approximated by [26].

$$
f=\frac{1}{2 \sqrt{\varepsilon_{0} \mu_{0}}} \frac{n}{200} \quad n=1,3,5, \ldots
$$

The corresponding $\varepsilon_{\mathrm{rms}}$ error (22) is shown in Figure 5. As may be observed, the approximate models introduce $\varepsilon_{\mathrm{rms}}$ error that is strongly dependent on the conductor resonant frequency. The best accuracy is obtained by $\mathrm{CI}$ model with $\varepsilon_{\mathrm{rms}}$ error that goes up to $5-10 \%$ around resonances. TL model introduces more significant $\varepsilon_{\mathrm{rms}}$ error with peaks up to $30 \%$.

Due to significant $\varepsilon_{\text {rms }}$ errors introduced by NEC reflection coefficient method, our further analysis will consider only CI and TL models.

Figure 6 shows the influence of the soil conductivity on the accuracy of the approximate models that correspond to Case 1.

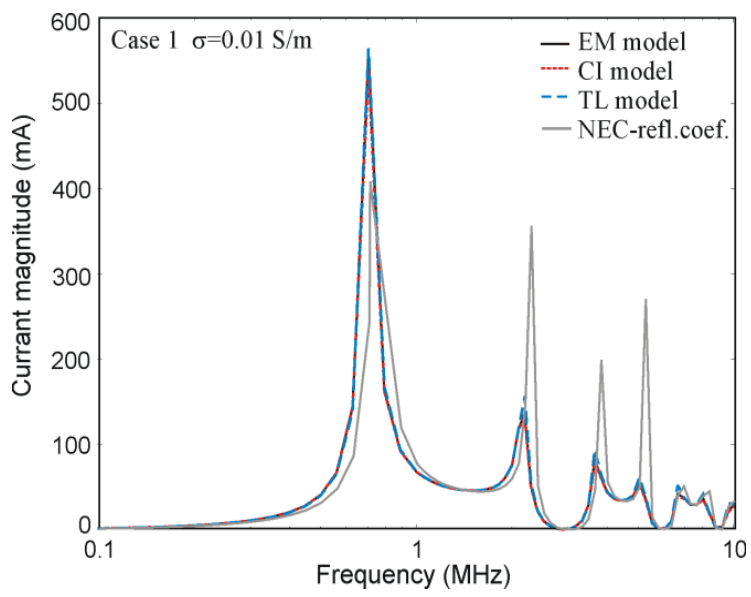

Fig. 4. Variations of the current magnitude at the center of the conductor for Case $1(\sigma=0.01 \mathrm{~S} / \mathrm{m})$ with respect to frequency

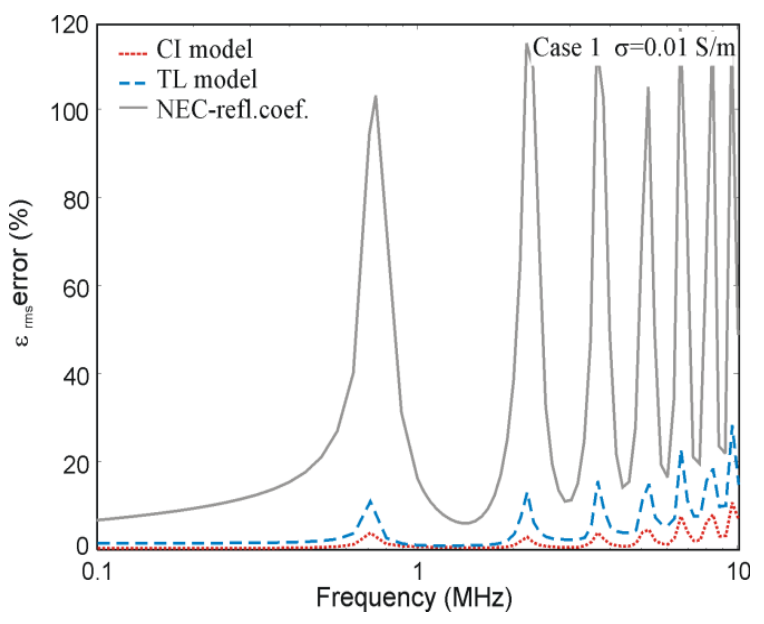

Fig. 5. $\varepsilon_{\text {rms }}$ error for Case $1(\sigma=0.01 \mathrm{~S} / \mathrm{m})$ 


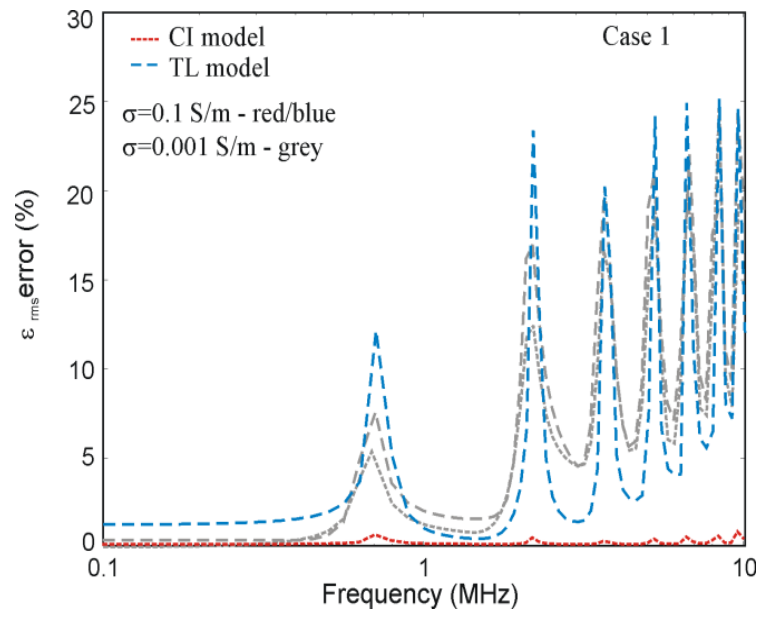

Fig. 6. Influence of the soil conductivity on the $\varepsilon_{\text {rms }}$ error for Case 1

When the soil is more conductive $(\sigma=0.1$ $\mathrm{S} / \mathrm{m}$ ) the accuracy of CI model increases and $\varepsilon_{\mathrm{rms}}$ error is less than $1 \%$ in all studied frequency range. However, when the soil is more resistive $(\sigma=$ $0.001 \mathrm{~S} / \mathrm{m}$ ) the peaks of the $\varepsilon_{\mathrm{rms}}$ error are above $10 \%$ and practically overlap with $\varepsilon_{\text {rms }}$ error obtained by TL model. The TL model shows also better agreement when the soil is more conductive, but these improvements in the accuracy can be seen in regions outside the resonance, while the peak values are larger.

\section{TWO-CONDUCTORS LINE}

In this section we analyze a two-conductor test-case shown in Figure 2, that considers three distinct geometries: Case 2-a, Case 2-b and Case 2c.

We proceed our study with the Case 2-a. Firstly, we analyze the influence of the distance between the conductors by assuming two values: $d_{y}$ $=0.5 \mathrm{~m}$ and $d_{y}=0.25 \mathrm{~m}$. The soil conductivity is $0.01 \mathrm{~S} / \mathrm{m}$.

Figure 7 shows the induced currents at $1 \mathrm{MHz}$ and $10 \mathrm{MHz}$. As may be observed, the currents along the two conductors (1) and (2) are identical, and show tendency to decrease when decreasing the distance $d_{y}$. However, this change of distance between the conductors has no influence on the accuracy of CI and TL models, as given in Figure 8. Next, we fix $d_{y}=0.5 \mathrm{~m}$ and we change the soil conductivity from $\sigma=0.001 \mathrm{~S} / \mathrm{m}$ to $\sigma=0.1 \mathrm{~S} / \mathrm{m}$. The corresponding $\varepsilon_{\mathrm{rms}}$ error is given in Figure 9.

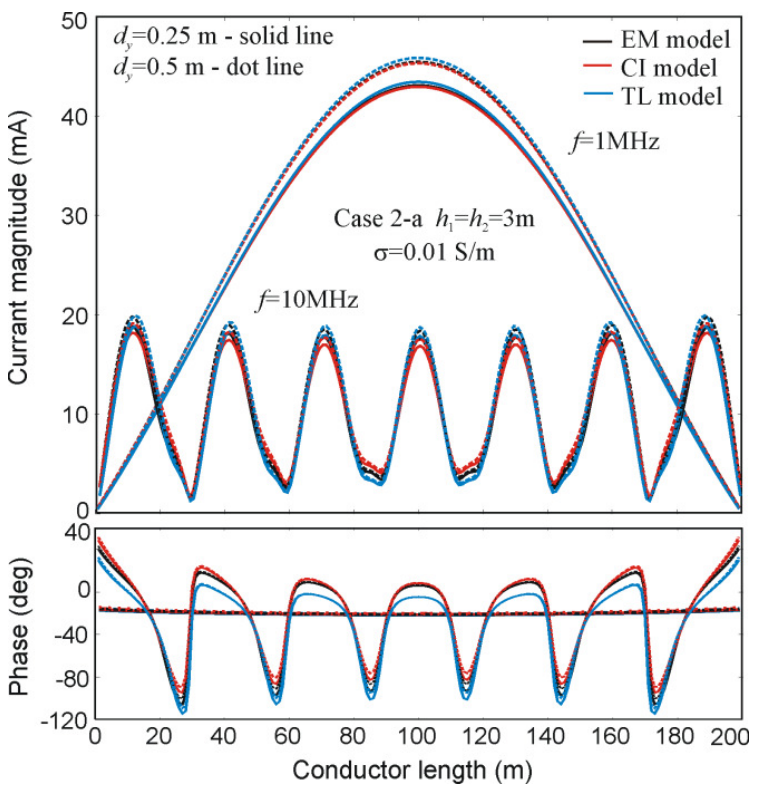

Fig. 7. Current distribution at $1 \mathrm{MHz}$ and $10 \mathrm{MHz}$ for Case $2(\sigma=0.01 \mathrm{~S} / \mathrm{m})$

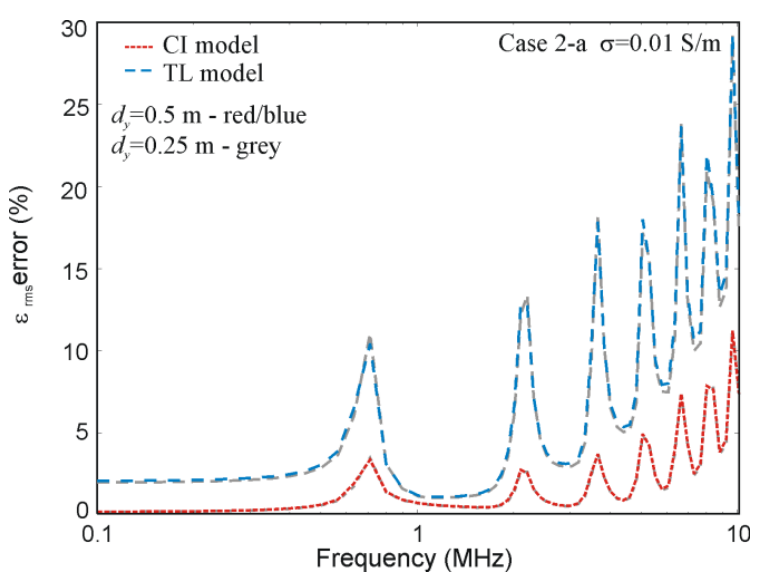

Fig. 8. Current at $1 \mathrm{MHz}$ and $10 \mathrm{MHz}$ for Case 2-a $(\sigma=0.01 \mathrm{~S} / \mathrm{m})$

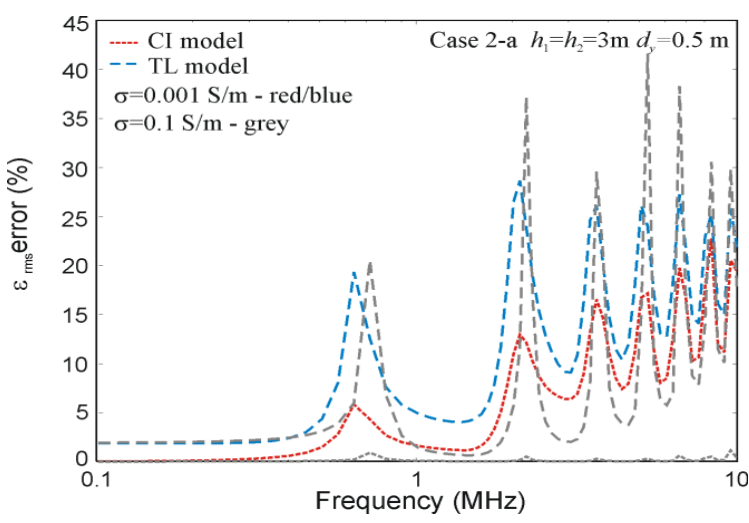

Fig. 9. $\varepsilon_{\mathrm{rms}}$ error for Case 2-a calculated for $d_{y}=0.5 \mathrm{~m}$ and $d_{y}=0.25 \mathrm{~m}$ 
As may be observed, the results confirm the previous conclusions about the influence of the soil conductivity on the accuracy of CI and TL models (Figure 6).

We continue our analysis with Case 2-b and Case 2-c. In both cases we consider two conductors placed at different heights: $h_{1}=3 \mathrm{~m}$ and $h_{2}=$ $3.5 \mathrm{~m}$. In Case 2-b the distance between the conductors is $d_{y}=0$, whereas in Case 2-c the distance between the conductors is $d_{y}=0.5 \mathrm{~m}$. The soil conductivity is $0.01 \mathrm{~S} / \mathrm{m}$.

Figure 10 shows the accuracy of CI and TL models applied to the previous cases. The results confirm that the distance $d_{y}$ has no influence on the accuracy of CI and TL models since lines in black (Case 2-b) and in grey (Case 2-c) overlap. When we compare with the previous Case 2-a (Figure 8) we can conclude that the $\varepsilon_{\text {rms }}$ error introduced by TL model is now larger. This increase in error is due to changes in the height of conductor (2), which is now $h_{2}=3.5 \mathrm{~m}$. However, this change of height $h_{2}$ does not affect the accuracy of CI model that remains the same as before.

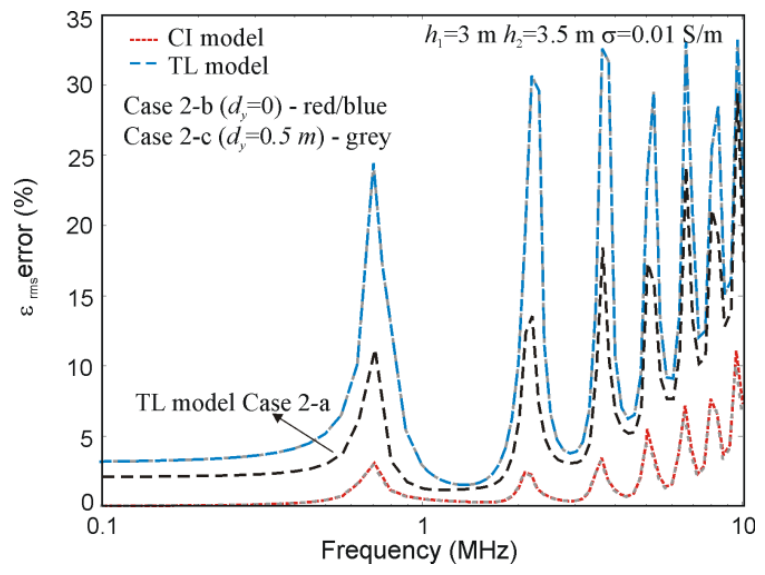

Fig. 10. Influence of the soil conductivity on the $\varepsilon_{\mathrm{rms}}$ error for Case 2-b and Case 2-c

\section{THREE-CONDUCTORS LINE}

In this section we analyze three geometries related to a three-conductor test-case given in Figure 2: Case 3-a, Case 3-b and Case 3-c.

The soil conductivity is $0.01 \mathrm{~S} / \mathrm{m}$. Figure 11 shows the induced currents calculated at $1 \mathrm{MHz}$ and $10 \mathrm{MHz}$ along the conductors (1) and (2), the currents along conductors (1) and (3) are equal. When comparing with the case of two conductors (Case 2-a) it may be observed that the magnitudes of the induced currents are generally decreased, and the current along the central conductor (2) is a slightly smaller than the currents along the outer conductors (1) and (3).

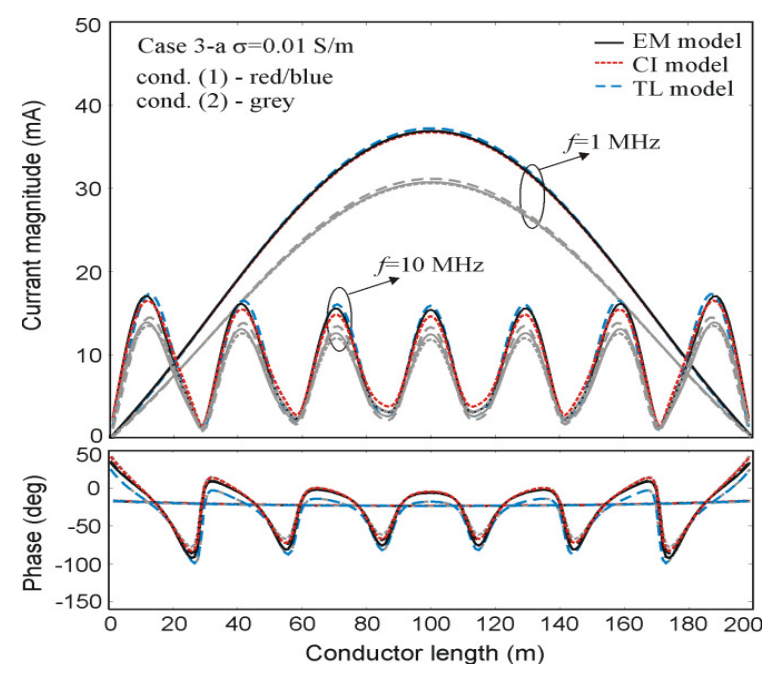

Fig. 11. Current distribution at $1 \mathrm{MHz}$ and $10 \mathrm{MHz}$ for Case 3-a $(\sigma=0.01 \mathrm{~S} / \mathrm{m})$

As shown in Figure 12, the corresponding $\varepsilon_{\mathrm{rms}}$ error introduced by TL model is higher than in the previous Case 2-a. However, CI model shows no differences in $\varepsilon_{\text {rms }}$ error with respect to previous cases.

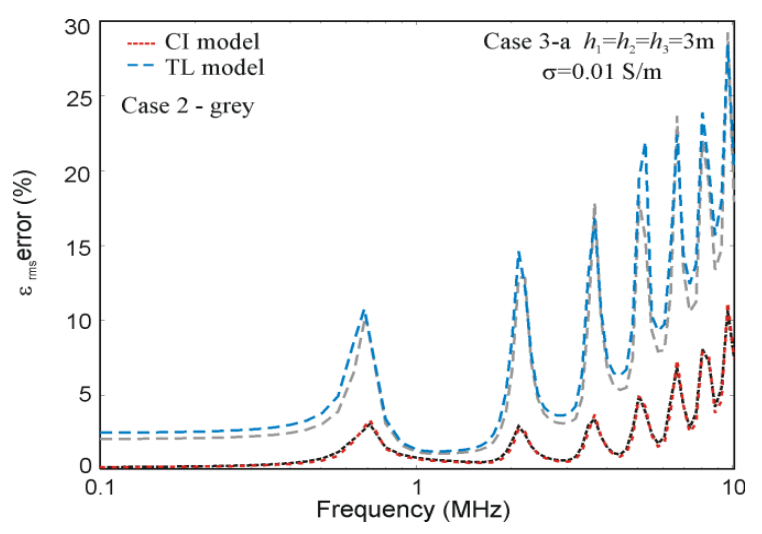

Fig. 12. $\varepsilon_{\mathrm{rms}}$ error for Case $3-\mathrm{a}(\sigma=0.01 \mathrm{~S} / \mathrm{m})$.

Next Figures. 13 and 14 show the current distribution along the three parallel conductors located at various heights $(2.5 \mathrm{~m}, 3 \mathrm{~m}$ and $3.5 \mathrm{~m})$, where the horizontal distance between the conductors is, respectively, $d_{y}=0$ (Case 3-b) and $d_{y}=0.5 \mathrm{~m}$ (Case 3-c). 


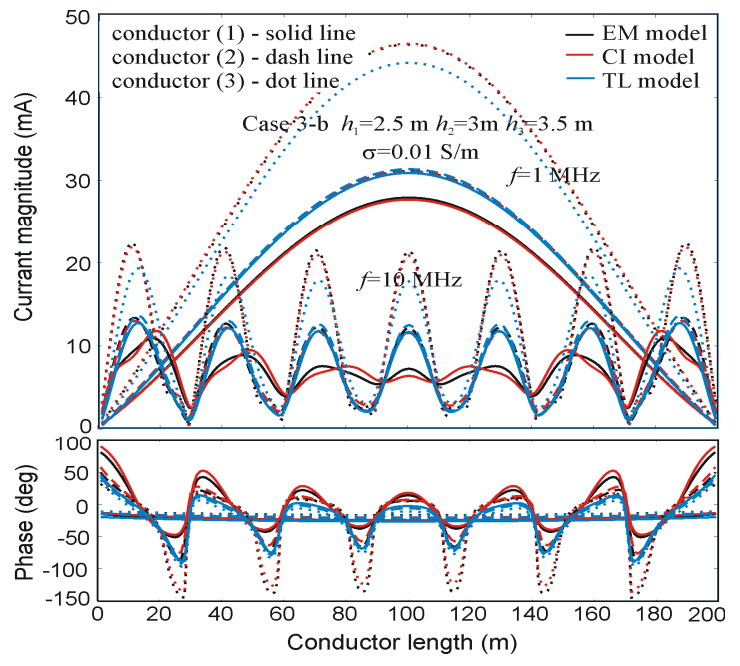

Fig. 13. Current distribution at $1 \mathrm{MHz}$ and $10 \mathrm{MHz}$ for Case 3-b ( $\left.\sigma=0.01 \mathrm{~S} / \mathrm{m}, d_{y}=0\right)$

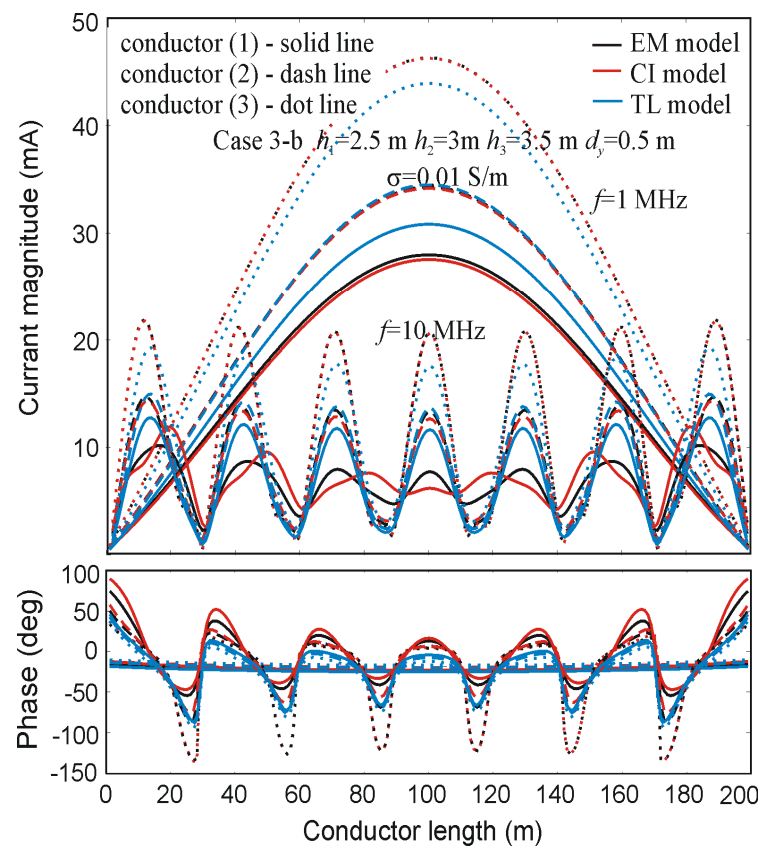

Fig. 14. Current distribution at $1 \mathrm{MHz}$ and $10 \mathrm{MHz}$ for Case 3-c $\left(\sigma=0.01 \mathrm{~S} / \mathrm{m}, d_{y}=0.5 \mathrm{~m}\right)$

In Figure 15 it is shown the $\varepsilon_{\text {rms }}$ error that corresponds to Case 3-b and Case 3-c. The results confirm that conductor's height affect strongly the accuracy of TL model. Again, no differences in $\mathcal{E}_{\mathrm{rms}}$ error are noticed between Case 3-b and Case 3$\mathrm{c}$, which is in agreement with our previous conclusion that the distance dy has no influence on the accuracy of TL model (Figure 8). The CI model shows stable accuracy with no changes in $\mathcal{E}_{\mathrm{rms}}$ error with respect to previous cases.

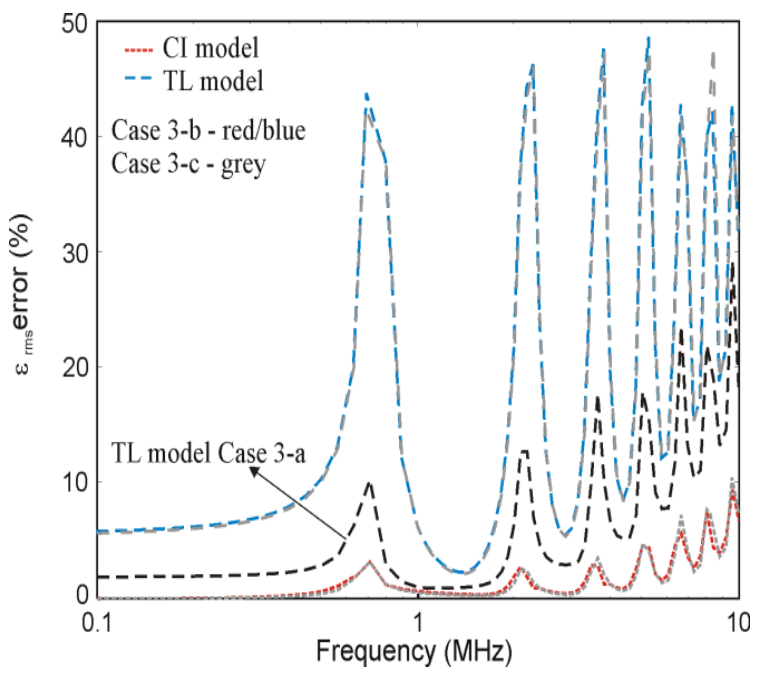

Fig. 15. $\varepsilon_{\mathrm{rms}}$ error for Case 3-b and Case 3-c $(\sigma=0.01 \mathrm{~S} / \mathrm{m})$

\section{CONCLUSIONS}

In this paper, we have compared the image and exact models of a wire that is above, below or penetrates a uniform or two-layered earth. The image model can be derived from the exact model by a single substitution of the reflection Fresnel coefficients in the spectral domain with their quasistatic forms.

The rigorous electromagnetic modeling of horizontal wire-conductors above lossy soil is considered as numerically most precise and accurate in a sense that it is based on least neglects.

In practice, however, simpler models are often required to avoid the complex computation and to reduce time consuming numerical calculations. In this paper, the authors present and compare two approximate approaches: CI model based on quasistatic complex image theory, and TL model based on transmission line theory with logarithmic expressions for per unit length ground impedance and admittance.

The results of a detailed wide frequency range numerical analysis of the induced currents along the studied test-cases (shown in Figure 2) may be summarized in:

The CI model is very accurate and leads to stable $\varepsilon_{\text {rms }}$ errors that are not influenced by: the number of conductors, conductor's height and distance between conductors. The $\mathcal{E}_{\mathrm{rms}}$ error shows dependence on frequency, but it is also significantly affected by the soil conductivity. In case of standard and high soil conductivity $(\sigma=0.01 \mathrm{~S} / \mathrm{m}$ 
and $0.1 \mathrm{~S} / \mathrm{m}$ ) the $\varepsilon_{\mathrm{rms}}$ error is within $10 \%$ and $1 \%$ respectively. The only exception when much higher $\varepsilon_{\text {rms }}$ errors are noticed is the case of low soil conductivity $(\sigma=0.001 \mathrm{~S} / \mathrm{m})$ when the peaks $\varepsilon_{\mathrm{rms}}$ error are about $25-30 \%$.

The accuracy of TL model shows also strong dependence on frequency with peaks at resonant frequencies. When increasing the soil conductivity, the $\varepsilon_{\mathrm{rms}}$ error is decreased in regions outside the resonances but the peaks are larger. The accuracy of TL models shows also significant dependence on geometry, i.e. the $\varepsilon_{\text {rms }}$ error increases when increasing the number of conductors and conductor's height.

The preliminary results obtained by using NEC reflection coefficient method show significant $\varepsilon_{\text {rms }}$ error that exceeds $100 \%$ at resonant frequencies, which makes this approach not suitable for calculations related to this problem.

\section{REFERENCES}

[1] Smith A. Jr.: Coupling of External Electromagnetic Fields to Transmission Lines, John Wiley and Sons, New York, 1935.

[2] Bridges, G. E. and Shafai, L.: Transient plane wave coupling to transmission lines above a lossy earth, In: Proceedings of Antennas and Propagation Society International Symposium, pp. 676-679, 1988.

[3] Bridges, G. E. and Shafai, L.: Plane Wave Coupling to Multiple Conductor Transmission Lines Above a Lossy Earth, IEEE Trans. Electromagn. Compat., Vol. 31., No. 1, pp. 21-33 (1989).

[4] Poljak, D., Doric, V., Rachidi, F., Drissi, K., Kerroum, K., Tkachenko, S. V., Sesnic, S.: Generalized form of telegrapher's equations for the electromagnetic field coupling to buried wires of finite length, IEEE Trans. Electromagn. Compat., Vol. 51, No. 2, pp. 331-337 (2009).

[5] Poljak, D., El Khamlichi Drissi, K., Kerroum, K., Sesnic, S.: Comparison of analytical and boundary element modeling of electromagnetic field coupling to overhead and buried wires, Eng. Anal. Bound. Elem., Vol. 35, pp. 555-563 (2011).

[6] Teshe, F. M., Ianosz, M., Karlsson, T.: EMC Analysis Methods and Computational Models, John Wiley and Sons, 1997.

[7] Burke, G. J. and Miller, E. K.: Modeling antennas near to and penetrating a lossy interface, IEEE Trans. Antennas Propag., Vol. AP-32, No. 10, pp. 1040-1049 (1984).

[8] Bannister, P.: Applications of complex image theory, Radio Sci., Vol. 4, 605-616 (1986).

[9] Bannister, P.: Summary of image theory expressions for the quasi-static fields of antennas at or above earth's surface, Proc. IEEE, Vol. 67, No. 7, pp. 1001-1008 (1979).
[10] Yang, J. J., Chow, Y. L. and Fang, D. G.: Discrete complex images of a three-dimensional dipole above and within a lossy ground, IEE Proc., Pt. H, Vol. 138, pp. 319-326 (1991).

[11] Arnautovski-Toševa, V., Grčev, L., and El Khamlichi Drissi, K.: Comparison of exact and image formulation of the electric field due to Hertz dipole in two-layer soil, Computer Field Models of Electromagnetic Devices, Vol. 34, pp. 621 - 629, (2010), IOS Press, Amsterdam.

[12] Arnautovski-Toševa, V.: Approximate closed-form solution of the electric field due to HED within finitely conductive earth, In: Proceedings of 13th International Conference on Electromagnetics in Advanced Applications, Turin, Italy, September 2011, pp. 1-4.

[13] Arnautovski-Toševa, V., El Khamlichi Drissi, K., Kerroum K., Grčeva, S., Grčev, L.: Comparison of image and transmission line models of energized horizontal wire above two-layer soil, Automatika, Vol. 53, No. 1, pp. 38-48 (2012).

[14] Arnautovski-Toševa, V., El Khamlichi Drissi, K., Grčev, L.: Effects of quasi-static approximation of green's functions in the model of a horizontal wire conductor in homogeneous soil, In: Proceedings of Advanced Electromagnetics Symposium, Paris, France, April 2012, pp. 15 .

[15] Arnautovski-Toševa, V., El Khamlichi Drissi, K., Kerroum, K.: comparison of approximate models of horizontal wire conductor above homogeneous ground, In: Proceedings of 6th European Conference on Antennas and Propagation, Prague, Czech Republic, March 2012. pp. 1-5.

[16] Arnautovski-Toševa, V. Gršev, L.: Electromagnetic analysis of horizontal wire in two-layered Soil, J. Comput. Appl. Math., Vol. 168, No. 1-2, pp. 21-29 (2004).

[17] Harrington, R. F.: Field Computation by Moment Method, IEEE Press, New York, 1993.

[18] Mosig, J. R.: Integral equation technique, Numerical Techniques for Microwave and Millimeter-Wave Passive Structures, T. Itoh (ed.), Wiley, New York, 1989 pp. 133-213.

[19] Michalski, K. A.: The mixed-potential electric field integral equation for objects in layered media, Arch. Elek. Übertragung., Vol. 39, No. 5, pp. 317-322 (1985).

[20] Chew, W. C.: Waves and Fields in Inhomogeneous Media, Van Nostrand Reinhold, New York, 1990, Ch. 2.

[21] Bannister, P. and Dube, R.: Simple Expressions for Horizontal Electric Dipole Quasi-Static Range Subsurface-toSubsurface and Subsurface-to-Air Propagation, Radio Sci., Vol. 3, pp. 501-507 (1978).

[22] Wait, J. R. and Spies, K. P.: On the image representation of the quasi-static fields of a line current source above the ground, Can. J. Phys., Vol. 47, pp. 2731-2733 (1969).

[23] Theethayi, N. and Thottappillil, R.: Surge Propagation and Crosstalk in Multiconductor Transmission Lines 
Above Ground, In: Electromagnetic Field Interaction with Transmission Lines, WIT Press, 2008.

[24] Paul, C. R.: Analysis of Multiconductor Transmission Lines, John Willey and Sons, New York, 1994.

[25] Poggio, A., Bevensee, R., Miller, E. K.: Evaluation of some thin wire computer programs, In: Proceedings of
IEEE Antennas and Propagation Symposium, Vol. 12, pp. 181-184 (1974).

[26] Myers, J. M., Sandler, S. S., Wu, T. T.: Electromagnetic resonances of a straight wire, IEEE Trans. Antennas Propag., Vol. 59, No. 1, pp. 129-1134, 2011.

[27] NEC-Numerical Electromagnetics Code (Method of Moments). [Online]. http://www.nec2.org/ 